\title{
Honorarios, Salarios, Hora cátedra y Prestaciones Sociales de los profesores universitarios
}

Jaime Ramírez Plazas Magister en Derecho Económico de la Universidad Externado de Colombia. Candidato a doctor en Sociología Jurídica de la misma Universidad. Profesor asociado de la Universidad Surcolombiana. Economista de la Universidad de los Andes, con Posgrados en Alta Gerencia - Universidad Surcolombiana, Instituciones Jurídicas Político y Derecho Público, de la Universidad Nacional y Docencia Universitaria de la Universidad Antonio Nariño.

Artículo recibido: 06/10/2008 Aprobado: 11/01/2009

jarapla@hotmail.com

\section{RESUMEN}

El presente artículo presenta la evolución de la remuneración de los profesores catedráticos de las universidades públicas y la formulación de un proyecto de Acuerdo que de cumplimiento a la sentencia C-006/96.

\section{PALABRAS CLAVE}

Honorarios, salarios, hora cátedra y prestaciones sociales

\section{ABSTRACT}

The overall objective is, on changes in the remuneration of teachers professors of public universities and the formulation of a draft agreement to comply with the ruling C-006/96.

\section{KEYWORDS}

Fees, salaries, time and social catedra.

\section{INTRODUCCION}

El estudio de los salarios es tema viejo (Ramírez Plazas, 2009 : 29), data de la economía clásica. No tan viejo, en cambio, es el estudio de los salarios en las instituciones de educación superior y menos aun la remuneración de los profesores catedráticos de las universidades ${ }^{1}$. Sobre el particular existe un acumulado representado en informes de consultoría encargados por gobiernos y organizaciones científicas y gremiales (Pérez Puente, 1958 : 252), y en bases de datos que guardan toda esa información².

La mayoría de estos informes sostienen que, en todos los países del mundo, los salarios del personal docente universitario han caído en términos reales y en comparación con otros oficios. Han perdido piso económico y prestigio social. Esto quiere decir, que, cada vez más, a los profesores universitarios nos miran por encima del hombro, no por excéntricos, sino por pobres, que es peor. Evidentemente esto no cuadra con la necesidad de contar con una educación de calidad en la sociedad del conocimiento.

El presente ensayo pretende mostrar la forma de remuneración de los profesores catedráticos de las universidades públicas en Colombia a lo largo de la historia desde una perspectiva legal que nos permita pasar de honorarios a hora cátedra.

${ }^{1}$ www.mineducacion.gov.co/.../article-87802.html

${ }^{2}$ Red de Revistas Científicas de América Latina y el Caribe, España y Portugal, Sistema de Información Científica Redalyc 


\section{ANTECEDENTES}

\subsection{Honorarios}

El artículo 128 de la Constitución Nacional prescribe:

"Nadie podrá desempeñar simultáneamente más de un empleo público ni recibir más de una asignación que provenga del tesoro público, 0 de empresas 0 de instituciones en las que tenga parte mayoritaria el Estado, salvo los casos expresamente determinados por la Ley.

Entiéndase por tesoro público el de la Nación, el de las entidades territoriales y el de las descentralizadas".

\section{El artículo 19 de la Ley $4^{\mathrm{a}}$ de 1992 establece:}

"Nadie podrá desempeñar simultáneamente más de un empleo público, ni recibir más de una asignación que provenga del tesoro público, o de empresas o de instituciones en las que tenga parte mayoritaria el Estado. Exceptúanse las siguientes asignaciones:

a) Las que reciban los profesores universitarios que se desempeñen como asesores de la rama legislativa;

\section{d) Los honorarios percibidos por concepto de hora - cátedra;}

g) Las que a la fecha de entrar en vigencia la presente Ley beneficien a los servidores oficiales docentes pensionados.

Parágrafo: No se podrán recibir honorarios que sumados correspondan a más de ocho (8) horas diarias de trabajo a varias entidades".

El término "asignación" comprende toda clase de remuneración que emane del tesoro público, llámese sueldo, honorario, mesada pensional, etc. ${ }^{3}$
El artículo 73 de la Ley 30 de 1992 consagraba:

"Los profesores de cátedra no son empleados públicos ni trabajadores oficiales; son contratistas y su vinculación a la entidad se hará mediante contrato de prestación de servicios, el cual se celebrará por períodos académicos.

Los contratos a que se refiere este artículo no estarán sujetos a formalidades distintas de las que se acostumbran entre particulares. El régimen de estipulaciones será el determinado por la naturaleza del servicio y el contrato podrá darse por terminado sin indemnización alguna en los casos de incumplimiento de los deberes previstos en la Ley o en el contrato.

Estos contratos requieren, para su perfeccionamiento, el registro presupuestal correspondiente".

Los contratos de prestación de servicios se cancelaban bajo la figura jurídica de honorarios que es la remuneración a la actividad, prestación o trabajo realizado por una persona natural - sin vínculo laboral- o jurídica, en el cual predomina el actor intelectual sobre el puramente material 0 mecánico.

El Decreto Ley 222 de 1983 y la Ley 80 de 1993 reglaron los contratos de prestación de servicios y han permitido la vinculación de personal para atender, entre otros, funciones que no podían serlo con el personal de planta.

En la Ley 80 de 1993, como en la Ley 190 de 1995 -Art. 32, numerales 3 y 20 , parágrafo único- se determina que los contratos de prestación de servicios no generan vinculación laboral ni prestaciones sociales. La precitada Ley 80 de octubre 28 de 1993, reglamentaria del nuevo régimen de la contratación administrativa y en alusión a los contratos de prestación de servicios, consagra lo siguiente:

${ }^{3}$ Corte Constitucional. Sentencia C- 133/93 abril 1 de 1993. Magistrado Ponente doctor Vladimiro Naranjo Mesa. Tema: Inconstitucionalidad del artículo 19 de la Ley 4 de 1992 
"Art. 32

$1 \ldots$

$2 \ldots$

3. Son contratos de prestación de servicios los que celebren las entidades estatales para desarrollar actividades relacionadas con la administración o funcionamiento de la entidad. Estos contratos sólo podrán celebrarse con personas naturales cuando dichas actividades no puedan realizarse con personal de planta 0 requieran conocimientos especializados.

En ningún caso estos contratos generan relación laboral ni prestaciones sociales y se celebrarán por el término estrictamente indispensable".

De otro lado, existieron algunas normas legales que regularon la vinculación por "contrato de prestación de servicios docentes", disposiciones a las cuales se sujetaron las distintas Administraciones para vincular de esa manera y en forma temporal a docentes 4 .

Se entiende que estas normas legales "especiales" sobre los contratos de prestación de servicios docentes, como lo dijo la Corte Constitucional ${ }^{5}$, fueron expedidas para resolver el problema de la atención educativa ante la parálisis de las plantas de personal docente. Las autoridades locales, en su momento, aplicaron estas Leyes al incorporar educadores por la vía contractual señalada.

En algunos casos, respecto de las Leyes $60 / 93$ y 115/94 -que reglaron aspectos de los contratos de prestación de servicios docentes- se ha propuesto la excepción de inconstitucionalidad; lo anterior para buscar la posibilidad de que la Jurisdicción ordene la posesión de los docentes vinculados de esta manera.

Pues bien, para el momento de la suscripción de muchos contratos de prestación de servicios docentes, estaba vigente la precitada legislación general y especial que permitía ese tipo de vinculación. Si se hubiera propuesto, en su momento, la excepción de inconstitucionalidad de tales normas legales, el resultado hubiera sido que las autoridades no hubieran podido vincular, ni siquiera contractualmente, a los educadores para atender las necesidades docentes, ya que por otro lado no existían vacantes en las plantas de personal docente.

La junisprudencia actual de la Sección $2^{\mathrm{a}}$ del $\mathrm{H}$. Consejo de Estado en cuanto a controversias de esta naturaleza tuvo la oportunidad de reestudiar la situación jurídica y fáctica y en la Sentencia de noviembre 30 de 2000 del Proceso No. 2888-99 se replantearon sus consideraciones y soluciones, por lo que a continuación se mencionan sus principales aspectos relevantes.

\section{e) De la relación entre las partes y los contratos de prestación de servicios.}

En la citada providencia se sostuvo que cabe anotar que no está demostrado que la autoridad, en su momento, al suscribir los contratos de prestación de servicios docentes, hubiera querido ocultar una relación laboral de derecho público; lo que aparece es que para resolver el problema de falta de profesores -en la planta de personal- aplicó la normatividad legal que le permitía vincular personal en esas condiciones.

Dijo que otra cosa es que ahora se demuestre que en la relación del docente temporal concurnieron los elementos esenciales de una relación de trabajo (actividad personal del trabajador, continuada subordinación respecto de la entidad empleadora y salario como retribución del servicio), criterio que es el aplicable en la Jurisdicción Ordinaria para determinar la relación laboral; pero resulta que en la Administración Pública, además, conforme a la Constitución es necesaria, la existencia del empleo en la planta de personal, de las funciones y de los recursos en el presupuesto para que una persona pueda ejercer el cargo y tener la calidad de empleado público o trabajador oficial.

“Consejo de Estado, Sección Cuarta, Radicación 7276, sentencia de 13 de octubre de1995. M:P Dr. Julio Enrique Correa Restrepo.

${ }^{5}$ Corte constitucional, Sentencia C-073/03 M:P Dr. Manuel José Cepeda Espinosa, expediente D-4270, cuatro (04) de febrero de dos mil tres (2003). 
Los contratos de prestación de servicio suscritos por los catedráticos, no le confirieron al contratista el carácter de docente oficial, porque para ello no se cumplen unos requisitos legales, ni tampoco es procedente calificarla de trabajador oficial, por cuanto los servidores de las entidades estatales que se dedican a la docencia, son empleados públicos.

La Corte Constitucional, mediante sentencia C 006 de 1996, dejó vigente sólo la parte inicial del artículo 73 de la Ley 30 de 1993 en la que se estatuye: "Los profesores de cátedra no son empleados públicos ni trabajadores oficiales".

\subsection{Salario}

La Constitución no ha señalado reglas expresas y precisas que permitan definir el concepto de salario, los elementos que lo integran ni sus efectos en la liquidación de prestaciones sociales. Por consiguiente, dichos aspectos corresponden a una materia que debe ser regulada por el legislador dentro de los criterios de justicia, equidad, racionalidad y razonabilidad, que necesariamente deben consultar los principios básicos que la Carta contiene, como son, entre otros, la igualdad, la garantía de una remuneración mínima, vital y móvil proporcional a la cantidad y calidad de trabajo, la irrenunciabilidad a los beneficios mínimos, y la primacía de la realidad sobre la formalidad.

Constituye salario no sólo la remuneración ordinaria, fija o variable sino todo lo que recibe el trabajador en dinero 0 en especie como contraprestación o retribución directa y onerosa del servicio. Es decir, no sería salario lo que recibe el trabajador a título gratuito o por mera liberalidad del empleador, lo que recibe en dinero o en especie para desempeñar a cabalidad sus funciones, las prestaciones sociales, los pagos o suministros en especie, conforme lo acuerden las partes, los pagos que según su naturaleza y por disposición legal no tienen carácter salarial, o lo tienen en alguna medida para ciertos efectos, los beneficios 0 auxilios habituales u ocasionales, acordados convencional o contractualmente $u$ otorgados en forma extralegal por el empleador, cuando por disposición expresa de las partes no tienen el carácter de salario, con efectos en la liquidación de prestaciones sociales.

Es de la competencia del legislador ${ }^{6}$, dentro de la libertad que tiene como conformador de la norma jurídica, determinar los elementos de la retribución directa del servicio dentro de la relación laboral subordinada, esto es, lo que constituye salario, con arreglo a los criterios y principios ya mencionados, lo cual le impide desconocer la primacía de la realidad sobre la forma y mudar arbitrariamente la naturaleza de las cosas, como sería quitarle la naturaleza de salario a lo que realmente tiene este carácter. Igualmente, dicha competencia se extiende a la determinación expresa, respetando los referidos criterios y principios, o deferirla a la voluntad de las partes, de los pagos o remuneraciones que no constituyen salario para los efectos de la liquidación de prestaciones sociales.

Esto último es particularmente admisible, dado que la existencia del contrato y de los acuerdos y convenios de trabajo como reguladores de las relaciones de trabajo es reconocida por la propia Constitución, en cuanto no menoscaben la libertad, la dignidad humana ni los derechos de los trabajadores.

En la Constitución el trabajo representa un valor esencial que se erige en pilar fundamental del Estado Social de Derecho, como se deduce del conjunto normativo integrado por el preámbulo y los arts. $1^{\circ}, 2^{\circ}, 25,39,48,53,34,55,56$ y 64 , en cuanto lo reconoce como un derecho en cabeza de toda persona a pretender y a obtener un trabajo en condiciones dignas y justas, e igualmente como una obligación social, fundada en la solidaridad social.

En virtud de su consagración como un derecho, nuestra Constitución compromete al Estado en el deber de protegerlo, creando, estimulando e incentivando las condiciones socioeconómicas

${ }^{6}$ Corresponde al Congreso de la República, de conformidad con lo dispuesto por el artículo 53 de la Carta, la definición y regulación del salario 
propicias que promuevan una oferta de oportunidades laborales para todas aquéllas personas en capacidad de trabajar, expidiendo la normatividad que asegure unas relaciones laborales "dignas y justas", con arreglo a los principios fundamentales básicos y mínimos ideados por el Constituyente y, en ejercicio de su capacidad de intervención, limitando los abusos que pueden engendrarse al amparo de las leyes del mercado y del principio de la autonomía de la voluntad, o regulando las condiciones requeridas para racionalizar la economía, con el fin de asegurar el pleno empleo de los recursos humanos, la distribución equitativa de las oportunidades y los beneficios del desarrollo, especialmente en lo laboral, y el mejoramiento de la calidad de vida de los trabajadores.

Bajo las ideas expuestas, se deduce que la Constitución constituye el orden normativo primario protector del derecho al trabajo, bien sea que se preste independientemente $\mathrm{o}$ bajo condiciones de subordinación, en las modalidades de contrato de trabajo o bajo una relación laboral, legal, estatutaria o reglamentaria.

En efecto, la variedad normativa que aquella contiene propenden el establecimiento de relaciones laborales justas, mediante la eliminación de factores de desequilibrio, que aseguren la vigencia y efectividad del principio de igualdad, la protección a ciertos sectores de trabajadores que se encuentran en situaciones de debilidad manifiesta o carecen de oportunidades para la capacitación laboral, y la consagración de un sistema contentivo de una protección jurídica concreta del trabajo que debe ser desarrollado por el legislador, a partir del señalamiento de unos principios mínimos fundamentales (art. 53).

La Constitución no ha señalado reglas expresas y precisas que permitan definir el concepto de salario, los elementos que lo integran ni sus efectos en la liquidación de prestaciones sociales. Por consiguiente, dichos aspectos corresponden a una materia que debe ser regulada por el legislador dentro de los criterios de justicia, equidad, racionalidad y razonabilidad, como se expresó en la sentencia C-470/95 ${ }^{7}$, que necesariamente deben consultar los principios básicos que aquélla contiene, como son, entre otros, la igualdad, la garantía de una remuneración mínima, vital y móvil proporcional a la cantidad y calidad de trabajo, la irrenunciabilidad a los beneficios mínimos, y la primacía de la realidad sobre la formalidad.

La noción de salario, y particularmente su valor como retribución al servicio que se presta a un empleador, representado en el principio a trabajo igual salario igual, lo ha deducido la Corte de distintas normas de la Constitución, en diferentes oportunidades. Así, en la sentencia T-143/95 de la Sala Segunda de Revisión de Tutela se expresó:

"Bajo el entendido de la especial situación de desigualdad que se presenta en las relaciones de trabajo, el legislador ha arbitrado mecanismos que de alguna manera buscan eliminar ciertos factores de desequilibrio, de modo que el principio constitucional de la igualdad, penetra e irradia el universo de las relaciones de trabajo".

"Precisamente, el principio a trabajo igual salario igual se traduce en una realización especifica y práctica del principio de igualdad".

\section{"Constitucionalmente el principio se deduce:}

- Del ideal del orden justo en lo social y lo económico, que tiene una proyección en las relaciones de trabajo (preámbulo, arts. 10, 20 y 25 C.P.)

- Del principio del reconocimiento a la dignidad humana, que necesariamente se manifiesta en la garantía del derecho al trabajo en condiciones dignas que aseguren un nivel de vida decoroso (arts. 10, 25 y 53 , inciso final C.P.).

- Del principio de igualdad, pues la naturaleza conmutativa del contrato de trabajo, traducida en la

${ }^{7}$ Corte Constitucional de Colombia, Sentencia C-470/95. M.P. Antonio Barrera Carbonell.

${ }^{8}$ Corte Constitucional de Colombia, Sentencia T-143/95. M.P. Antonio Barrera Carbonell. 
equivalencia de las prestaciones a que se obligan las partes, el suministro de la fuerza de trabajo a través de la prestación del servicio, y la remuneración o retribución mediante el salario, se construye bajo una relación material y jurídica de igualdad que se manifiesta en el axioma de que el valor del trabajo debe corresponder al valor del salario que se paga por este (art.13C.P.).

- De los principios sobre la igualdad de oportunidades, que supone naturalmente no sólo la correspondencia o el balance que debe existir entre el valor del trabajo y el valor del salario, sino con respecto a los trabajadores que desarrollan una misma labor en condiciones de jornada y eficiencia iguales; el establecimiento de la remuneración mínima vital y móvil "proporcional a la calidad y cantidad de trabajo", e incluso, la "irrenunciabilidad de los beneficios mínimos" establecidos en las normas laborales, pues el trabajo realizado en ciertas condiciones de calidad y cantidad tiene como contraprestación la acreencia de una remuneración mínima que corresponda 0 sea equivalente a dicho valor (art. 53 C.P.)".

\section{(....)}

"Pero debe agregarse que el sustrato filosófico que subyace en el principio, se revela en el sentido de que lo que básicamente se reconoce es una relación de equivalencia de valores prestacionales, a modo de justicia conmutativa, en cuanto a lo que da o suministra el trabajador al patrono y lo que éste recibe a cambio, lo cual se adecúa a los valores constitucionales de la justicia, la igualdad y el orden justo".

"Cabría agregar además que el principio traduce igualmente la proyección de la democracia en las relaciones de trabajo porque estas al igual que aquélla se construyen básicamente sobre la idea de la igualdad jurídica y la igualdad material"'.

Uno de los elementos del Contrato de trabajo es la remuneración, la cual consiste en la contraprestación que el empleado da en dinero o en especie al trabajador por su trabajo.

La remuneración puede darse en efectivo o en especie, caso en el cual el salario en especie no puede superar el $50 \%$ del total del salario, y tratándose del salario mínimo, máximo se puede pagar en especie hasta un $30 \%$.

Constituye salario no sólo la remuneración ordinaria, fija o variable, sino todo lo que recibe el trabajador en dinero o en especie como contraprestación directa del servicio, sea cualquiera la forma o denominación que se adopte, como primas, sobresueldos, bonificaciones habituales, valor del trabajo suplementario o de las horas extras, valor del trabajo en días de descanso obligatorio, porcentajes sobre ventas y comisiones. (Art. 127 C.S.T).

De la norma transcrita se entiende que todo pago hecho al trabajador, no importa el concepto 0 definición que se le den hace parte del salario. Ahora, el pago que se haga al trabajador debe corresponder a la retribución que el empleador hace al trabajador por la prestación de sus servicios. Esto quiere decir, que aquellos pagos que no corresponden a una contraprestación por la labor del trabajador, no pueden considerarse salario, como bien es el caso de las indemnizaciones, viáticos (en los términos del Art. 130 del C.S.T), pagos por mera liberalidad del empleador, etc.

El derecho al salario es irrenunciable y no se puede ceder en todo ni en parte, a título gratuito ni oneroso pero sí puede servir de garantía hasta el límite y en los casos que determina la Ley (Art. 142 C.S.T).

El artículo 143 del Código Sustantivo del Trabajo establece que "a trabajo igual desempeñado en puesto, jornada y condiciones de eficiencia también iguales, debe corresponder salario igual, comprendiendo en éste todos los elementos a que se refiere el artículo 127" lo que supone que no debe haber una discriminación del empleado por su condición de sexo, edad, origen, raza, etc. No es legal, por

${ }^{9}$ Corte Constitucional. Sentencia No. C-521/95 Magistrado Ponente: Dr. Antonio Barrera Carbonell 
ejemplo, que a un empleado le paguen menos que a otro que cumple exactamente la misma función y en las mismas condiciones.

En concepto del 26 de marzo de 1992, la Sala de Consulta y Servicio Civil del Consejo de Estado se expresó que remuneración es todo lo devengado por el empleado o trabajador como consecuencia directa 0 indirecta de su relación laboral. Comprende, en consecuencia, los sueldos, primas, bonificaciones y demás reconocimientos que se hagan directa o indirectamente por causa o razón del trabajo o empleo, sin ninguna excepción. Es equivalente al salario, pero esta denominación de ordinario se reserva a la retribución que perciben las personas vinculadas por contrato de trabajo.

Sin embargo, el principio constitucional de la primacía de la realidad sobre las formalidades establecidas por los sujetos de las relaciones laborales, previsto en el artículo 53 de la Constitución Política, permite analizar si bajo la apariencia de un contrato se pretende ocultar una relación estatutaria o legal, para determinar luegola posibilidad de que el vínculo que ata al docente con la administración es de índole laboral con las consecuencias que permite el ordenamiento jurídico.

\subsection{Derecho al salario}

LaConstitución Política de 1991 establece:

"Art. 122 No habrá empleo público que no tenga funciones detalladas en Ley o reglamento y para proveer los de carácter remunerado se requiere que estén contemplados en la respectiva planta y previstos sus emolumentos en el presupuesto correspondiente. (inc. $1^{\circ}$ )..."

Art. 125 Los empleos en los órganos y entidades del Estado son de carrera. Se exceptúan los de elección popular, los de libre nombramiento y remoción, los de trabajadores oficiales y los demás que determine la Ley. Los funcionarios, cuyo sistema de nombramiento no haya sido determinado por la Constitución o la Ley, serán nombrados por concurso público.

El ingreso a los cargos de carrera y el ascenso en los mismos se harán previo cumplimiento de los requisitos y condiciones que fije la Ley para determinar los méritos y calidades de los aspirantes. (..)."

El docente contratista no tiene los mismos derechos y prerrogativas de los docentes oficiales vinculados con relación legal y reglamentaria; en principio, no podría tener la virtualidad de dejar sin efecto el contrato de prestación de servicios docentes para convertir dicha relación en legal y reglamentaria porque para que se diera este paso es necesario que desde su iniciación se hubieran cumplido varios requisitos legales que no se dieron, como se analizará posteriormente ${ }^{10}$.

No obstante, como los catedráticos cumplen labores similares a las que realiza un funcionario oficial, la jurisdicción, en aras de la protección a términos de los artículos 13 y 25 de la Carta, les ha reconocido una relación laboral limitada, permitida en la Sentencia C-555 de 1994.

" ... El principio de la primacia de la realidad sobre las formalidades establecidas por los sujetos de las relaciones laborales, no tiene, adicionalmente, el alcance de excusar con la mera prestación efectiva de trabajo la omisión del cumplimiento de los requisitos constitucionales y legales previstos para acceder a la función pública que, en la modalidad estatutania, son el nombramiento y la posesión, los que a su vez presuponen la existencia de un determinado régimen legal y reglamentario, una planta de personal y de la correspondiente disponibilidad presupuestal.

El mencionado principio agota su cometido al desentrañar y hacer triunfar la relación de trabajo sobre las apariencias que hayan querido ocultarla. Y esta primacía puede imponerse tanto frente a

${ }^{10}$ Consejo de Estado, Sala de lo Contencioso Administrativo, Sección Segunda Subsección "A", Bogotá, D.C., veintiséis (26) de enero de dos mil seis (2006), Exp.: 25000232500020011068801. MAGISTRADA PONENTE: ANAMARGARITA OLAYAFORERO. 
particulares como al Estado mismo. Su finalidad no puede dilatarse hasta abarcar como función suya la de aniquilar las que son formalidades sustanciales de derecho público, formalidades que traducen principios de organización del Estado de Derecho, indisponibles para las autoridades que les deben acatamiento y que ninguna práctica, por generalizada que sea, es capaz de sustituir 0 derogar.

Sin embargo, a partir de esta premisa, no podrá en ningún caso conferirle el estatus de empleado público, sujeto a un específico régimen legal y reglamentario. El principio de la primacía de la realidad sobre las formalidades establecidas por los sujetos de las relaciones laborales no tiene, adicionalmente, el alcance de excusar con la mera prestación efectiva de trabajo la omisión del cumplimiento de los requisitos constitucionales y legales previstos para acceder a la función pública que, en la modalidad estatutaria, son el nombramiento y la posesión, los que a su vez presuponen la existencia de determinado régimen legal y reglamentario, una planta de personal y de la correspondiente disponibilidad presupuestal"...

"La mera prestación de trabajo, así beneficie al Estado, se comprende, aparte de calificarse como relación laboral y derivar de ella los derechos contemplados en las normas que la regulan, no coloca a la persona que la suministra en la misma situación legal y reglamentaria en la que pueda encontrarse otra persona que desempeña como empleado público una actividad similar.

Admitir que ello pudiera ser asi, significaría hacer caso omiso de:

(1) La existencia de un acto administrativo que ordene la respectiva designación, que es sustituido por una simple práctica realizada al margen de las condiciones constitucionales y legales que deberían darse para poder producir la vinculación;

(2) La posesión para tomar el cargo, de modo que sigilosamente pueden ingresar al servicio público personas que no asumen públicamente el compromiso de obedecer la Constitución y las Leyes;

(3) Planta de personal que no contempla el empleo o cargo que mediante la vía de hecho pretende consolidarse;

(4) La disponibilidad presupuestal para atender el servicio, con lo cual se pueden generar obligaciones que superan las posibilidades fiscales, además por parte de personas y autoridades no autorizadas para gravar el erario público y a través de procedimientos no democráticos;

(5) Las regulaciones generales que gobiernan el ejercicio, las responsabilidades públicas y la forma de remunerarlas, las cuales son sustituidas por estipulaciones que, por desconocer el régimen legal, representan una invasión de poderes que son del resorte del Congreso, las Asambleas o los Concejos, o de otras autoridades".

Señaló que en ese evento es dado mencionar el criterio jurisprudencial expresado en la sentencia del 15 de junio de 1992, del Exp. No. 4058, con ponencia del Consejero Dr. Álvaro Lecompte Luna. En aquella oportunidad dijo la Sala:

“... La calificación de la naturaleza jurídica del vínculo laboral que une a un funcionario con la administración, no puede ser establecida por la voluntad de las partes o modalidades del acto a través del cual se llevó a cabo la vinculación, sino por las normas legales. Por ende, puede haberse vinculado un funcionario a un establecimiento público por contrato de trabajo, pero si las normas que regulan al organismo no permiten que la actividad que va a realizar el empleado, pueda ser cumplida mediante esta modalidad contractual, éste no puede ser calificado como trabajador oficial..."

\subsection{De los salarios y prestaciones}

Se dijo que la Corte Constitucional en la Sentencia C-555/94 señaló que el régimen salarial se aplica a los docentes integrados a las plantas de personal por acto administrativo, pero que esas normas no 
se extienden a los docentes contratistas. Además, los docentes contratistas pactaron unos honorarios como retribución por su trabajo; dicho contrato no aparece que haya sido anulado y produjo efectos en derecho.

Agregó que no obstante, en aras de preservar la equidad hasta donde es posible, la Jurisdicción ha accedido a reconocer a título de INDEMNIZACIÓN, el equivalente a las prestaciones sociales que perciben los docentes oficiales (de la respectiva Entidad Contratante), tomando el valor de lo pactado en el contrato de prestación de servicios, como base para la liquidación de la indemnización, tal como se expresó claramente en la Sentencia de marzo 18/98 del Exp. No. 11722 - 1198/98, de la Sección $2^{\mathrm{a}}$ del Consejo de Estado, con ponencia del Dr. Flavio Rodríguez.

Y para tal efecto, se deben determinar inicialmente cuáles son esas prestaciones ordinarias a que tienen derecho los educadores oficiales (v.gr. prima de navidad, cesantía, etc.) y la forma de su liquidación (v.gr. número de días y valores, etc.), para después calcular, teniendo en cuenta esos parámetros y el valor de esas prestaciones que no pudieron devengar, conforme a los honorarios pactados $^{11}$.

\section{Elartículo 74 de la misma Ley 30 de 1992 preveía:}

"Serán profesores ocasionales aquellos que con dedicación de tiempo completo o de medio tiempo, sean requeridos transitoriamente por la entidad para un período inferior a un año.

Los docentes ocasionales no son empleados públicos ni trabajadores oficiales, sus servicios serán reconocidos mediante resolución y no gozarán del régimen prestacional previsto para estosúltimos".

La Corte Constitucional en sentencia C-006 de 1996 declaró inexequible el aparte del inciso segundo del artículo 74 de la Ley 30 de 1992 "... yno gozarán del régimen prestacional previsto para estosúltimos".

La Corte Constitucional, en sentencia C - 006 / 96 , sostuvo:

"Decidir que el régimen aplicable a los profesores ocasionales es el mismo que la Ley estableció para los supernumerarios, tal como se solicita en el concepto fiscal, implica el ejercicio de una actividad legislativa que no le corresponde a esta Corporación. Su decisión, al declarar la inconstitucionalidad de la disposición acusada del artículo 74 de la Ley 30 de 1992, implica el reconocimiento de los derechos que como servidores del Estado tienen dichos docentes, los cuales constituyen una modalidad de trabajo que como tal gozan de especial protección por parte del Estado. En este sentido los profesores ocasionales de las universidades estatales u oficiales, a los que se refiere dicha norma, tendrán derecho, a partir de la fecha de este pronunciamiento, al reconocimiento proporcional de las prestaciones sociales que se aplican a los profesores empleados públicos de carrera, de que trata el artículo 72 de la citada Ley 30 de 1992."

"Ahora bien, esta misma interpretación cabe aplicarla a los profesores de cátedra a que se refiere el articulo 73 de la misma Ley, pues ellos son servidores públicos que están vinculados a un servicio público y en consecuencia los respectivos actos administrativos determinarán las modalidades y efectos de su relación jurídica de acuerdo con la Ley."

"En efecto, como se ha sostenido anteriormente, estos profesores de cátedra tienen también una relación laboral subordinada, por cuanto cumplen una prestación personal de servicio, igual a la que realizan los profesores de tiempo completo, de medio tiempo o los llamados ocasionales a que se refiere el articulo 74. Ellos devengan una remuneración por el trabajo desempeñado y están sujetos a una subordinación como se les exige a los

${ }^{11}$ Consejo de Estado, Sala de lo Contencioso Administrativo, Sección Segunda-subsección "B", Bogotá. D.C., veintiocho (28) de agosto del dos mil tres (2003), Radicación número: 73001-23-31-000-1999-0454-01. CONSEJERO PONENTE: TARSICIO CÁCERES TORO. 
otros, como horario, reuniones, evaluaciones, etc., contemplados en el reglamento."

"Entonces frente a esta similar situación de hecho que identifica la misma relación de trabajo subordinado de estos servidores públicos, debe corresponderles el mismo tratamiento en cuanto a prestaciones sociales, que deben pagárseles proporcionalmente al trabajo desempeñado. Otro tratamiento desconoceria el principio de igualdad y de justicia y seria evidentemente discriminatorio. Por tanto se declarará también la inexequibilidad por unidad normativa del aparte del artículo 73 de la misma Ley,"

El Consejo de Estado $^{12}$ en relación con la vinculación de los empleados públicos como catedráticos de las universidades públicas, dijo:

1. Se puede seguir vinculando a empleados públicos y trabajadores oficiales para que presten el servicio de docencia mediante el sistema hora cátedra, el que debe ser remunerado, correspondiéndoles las prestaciones sociales que fija la Ley a los servidores del Estado, proporcionalmente al trabajo desempeñado.

2. La relación entre el docente de hora - cátedra y la institución de educación superior oficial en la que presta estos servicios no es la misma que se da con el empleado público o el trabajador oficial. Es una relación de carácter laboral, de naturaleza especial, de tipo convencional, sometida en cada caso a lo previsto en la Ley, y en los estatutos y reglamentos de la respectiva institución de educación superior.

3. Los pensionados del sector público pueden prestar el servicio de docentes de hora - cátedra y recibir las prestaciones sociales correspondientes.

\subsection{La Hora Cátedra}

La Sentencia C-006/96 ${ }^{13}$ dejó sentado que los establecimientos de educación superior no pueden vincular profesores hora cátedra a través de contrato civil de prestación de servicios, pues la relación que existe entre éstos y la respectiva institución es eminentemente laboral y cumple fielmente las condiciones o requisitos del contrato realidad. Ello impide, en consecuencia, cualquier restricción a sus derechos constitucionales y legales, particularmente, los derivados de las prestaciones sociales, que por razón del carácter transitorio de la actividad académica desarrollada, deben reconocerse en proporción al tiempo de servicio.

Las remuneraciones de los docentes de hora cátedra vinculados mediante contratos de prestación de servicios a las universidades públicas del orden nacional se liquidarán según su categoría equivalente en el escalafón, y de acuerdo con las horas efectivamente dictadas ${ }^{14}$.

Según el nivel equivalente en el escalafón, los valores de la hora cátedra en puntos, serán los siguientes:

a) Para el equivalente a instructor 0 profesor auxiliar, instructor asistente, uno y un cuarto (1.25) puntos.

b) Para el equivalente a profesor asistente, dos (2) puntos.

c) Para el equivalente a profesor asociado, dos y un cuarto (2.25) puntos;

d) Para el equivalente a profesor titular, dos y medio (2.5) puntos;

e) Para el equivalente a instructor asociado, en el caso de la UN de Colombia, uno y medio (1.5) puntos.

La remuneración de los docentes de cátedra de la Universidad Nacional se obtiene de dividir por 100 la remuneración mensual correspondiente a la dedicación de tiempo completo que acredite el docente de cátedra ${ }^{15}$.

En las instituciones de educación superior

\footnotetext{
${ }^{12}$ Consejo de Estado - Sala de Consulta y Servicio Civil. Radicación 880 de 1996

${ }^{13}$ Corte Constitucional. Sentencia No. C-006/96Magistrado Ponente: Dr. Fabio MORÓN DíAZ

${ }^{14}$ Decreto 1444/92. Artículo 12 (derogado por el Decreto 1279/02)

${ }^{15}$ Decreto 1279 de 2002. Artículo 27.
} 
privadas ${ }^{16}$, la vinculación se hará por horas cuando la carga sea inferior a la de medio tiempo.

En ningún caso podrá ser inferior al valor de cómputo hora resultante del valor total de 8 salarios mínimos dividido por el número de horas laborables mes.

El Decreto 2912 de 2001 , en su Artículo $24^{\circ}$ dispuso las remuneraciones de los docentes de cátedra así:

1. Las remuneraciones de los profesores de cátedra vinculados a las universidades oficiales 0 estatales del orden nacional, departamental, distrital o municipal, se liquidan según su categoría equivalente en el escalafón, y de acuerdo con las horas efectivamente dictadas.

Según el nivel equivalente en el escalafón, los valores de la hora-cátedra en puntos son los siguientes:

a. Para el equivalente a Instructor o Profesor Auxiliar, o Instructor Asistente, uno con setenta y cinco (1.75) puntos. Este es el puntaje mínimo para lahora-cátedra.

b. Para el equivalente a Profesor Asistente, hasta dos con cinco (2.5) puntos.

c. Para el equivalente a Profesor Asociado, hasta tres (3.0) puntos.

d. Para el equivalente a Profesor Titular, hasta tres con cinco (3.5) puntos. En el caso de un Profesor Titular o equivalente, con Ph.d o doctorado y menos de tres años de experiencia profesional, investigativa 0 docente, hasta tres con setenta y cinco (3.75) puntos. Si la experiencia es superior a tres años y el docente con doctorado acredita productividad académica relevante, hasta cuatro con veinticinco (4.25) puntos.

e. Para el equivalente a Instructor Asociado, en el caso de la Universidad Nacional de Colombia, hastados (2.0) puntos. f. Para los docentes de cátedra que desempeñan su labor en programas de Doctorado, la Universidad puede asignar el número de puntos para la hora cátedra.

g. Para la asignación del puntaje se tiene en cuenta si el profesor desempeña sus labores en pregradoo posgrado, los titulos del docente, su experiencia y su productividad.

En Colombia el Decreto 1279 de 2002, Por el cual se establece el régimen salarial y prestacional de los docentes de las universidades estatales dispone en su artículo 4 que los profesores de horacátedra de las universidades estatales u oficiales distintas a la Universidad Nacional de Colombia no son empleados públicos docentes de régimen especial ni pertenecen a la carrera profesoral y, por consiguiente, sus condiciones salariales y prestacionales no están regidas por el Decreto, sino por las reglas contractuales que en cada caso se convengan, conforme a las normas internas de cada Universidad, con sujeción a lo dispuesto en las disposiciones constitucionales y legales.

Con base en lo anterior, es competencia de los Consejos Superiores de las universidades públicas establecer el valor de la hora cátedra y el reconocimiento de las prestaciones sociales proporcionales a los catedráticos de las universidades públicas

Las normas que han expedido los Consejos Superiores Universitarios hasta la fecha con base en las cuales se define el valor de la hora cátedra son las siguientes:

Acuerdo No 031 de 1994, Universidad del Tolima Acuerdo $\mathrm{N}^{\circ} 049$ de 1995, Universidad del Quindio Acuerdo No.046 de 2002, Universidad de Pamplona

Acuerdo No 059 de 2002, Universidad de la Amazonia

Acuerdo No. 018 de 2003, Universidad del Cauca Acuerdo No 253 de 2003, Universidad de Antioquia Acuerdo No. 024 de 2003, Universidad del Valle

${ }^{16}$ Ley 30 de 1992. Artículo 106. 
Acuerdo No 007 de 2003, Universidad del Magdalena

Acuerdo No. 29 de 2004, Universidad Tecnológica dePereira

Acuerdo No 009 de 2004, Escuela Superior de Administración Pública -ESAP

Acuerdo 002 del 2004, Universidad de los LLanos

Acuerdo $N^{\circ} 016$ de 2005, Universidad Nacional de Colombia

Acuerdo No 201 de 2005, Universidad de Caldas

Acuerdo No.026 de 2005, Universidad Francisco de Paula Santander

Acuerdo No 08 de 2008, Universidad Militar Nueva Granada

Acuerdo No. 68 de 2008, Universidad Industrial de Santander

Acuerdo No. 15 de 2009, Universidad Pedagógicay Tecnológica de Colombia

Acuerdo No. 15 de 2009, Universidad Surcolombiana.

\subsection{Hora Cátedra y Prestaciones Sociales de los catedráticos}

Con base en la sentencia C-006/96 de la Corte Constitucional se tiene que los profesores catedráticos de las universidades públicas tienen derecho al reconocimiento de prestaciones sociales en términos proporcionales a las que devengan los profesores de tiempo completos establecidas en los artículos 33 a 49 del Decreto 1279 de 2002 a saber: vacaciones, prima de vacaciones, bonificación por servicios prestados, prima de servicio, prima de navidad, cesantías, pensiones y salud.

Con el fin de determinar el valor de la hora cátedra, dándole estricto cumplimiento a la sentencia C006/96, se debe inicialmente establecer la categoría del docente catedrático universitario, a saber: instructor, asistente, asociado y titular. Luego se establecen los puntos a que tiene derecho de conformidad con el articulo 6 del Decreto 1279 de 2002, de acuerdo con la valoración de los siguientes factores:

a. Los títulos correspondientes a estudios universitarios.

b. La categoría dentro del escalafón docente.

\section{c. La experiencia calificada.}

d. La productividad académica.

Con base en el número de puntos que tenga el catedrático se multiplica por el valor del punto determinado por el Gobierno Nacional y se divide por 180 equivalentes a las horas laboradas mensualmente por un docente de tiempo completo, de conformidad con lo dispuesto por el artículo 71 de la Ley 30 de 1992.

El valor proporcional da cada prestación a la que tienen derecho los profesores catedráticos con base en la sentencia C006/96 es el siguiente:

$\begin{array}{ll}\text { PRESTACIÓN } & \text { FACTOR } \\ \text { Bonificación por servicios } & 0.0292 \\ \text { Prima de servicios } & 0,0857 \\ \text { Prima de vacaciones } & 0,0649 \\ \text { Vacaciones } & 0,0926 \\ \text { Prima de Navidad } & 0,0978 \\ \text { Cesantías } & 0,11168 \\ \text { Intereses a las cesantías } & 0,12 \\ \text { Pensión } & 0,11625 \\ \text { Salud } & 0,085 \\ \text { ICBF } & 0,03 \\ \text { Cajas de Compensación Familiar } & 0,04\end{array}$


Teniendo en cuenta los factores anteriores, se presenta un modelo de Acuerdo que, determinando el valor de la hora cátedra, permita reconocer las prestaciones sociales de los catedráticos, dándole estricto cumplimiento a la sentencia C-006/96 de la Corte Constitucional.

\section{ACUERDO No DE 2009 (Mes y día)}

Por el cual se aprueba el Régimen prestacional del Profesor de Cátedra de la Universidad XXXXX.

\section{EL CONSEJO SUPERIOR DE LAUNIVERSIDAD XXXXXXX}

en uso de sus atribuciones legales, y

\section{CONSIDERANDO:}

Que el artículo 13 de la Constitución Nacional que consagra la igualdad real y efectiva de derechos y oportunidades para todas las personas y el artículo 25 de la misma Carta consagran la especial protección del Estado para todas las modalidades de trabajo y las condiciones dignas y justas del mismo.

Que el artículo 69 de la Constitución Nacional garantiza la autonomia universitaria y permite que las universidades puedan darse sus directivas y regirse por sus propios estatutos, de acuerdo con la Ley.

Que la Ley establece un régimen especial para las universidades del Estado.

Que el artículo 2 de la Ley $4^{\mathrm{a}}$ de 1992 dispone que para la fijación del régimen salarial y prestacional de los servidores públicos, el Gobierno Nacional tendrá en cuenta los siguientes objetivos y criterios:

a) El respeto a los derechos adquiridos de los servidores del Estado tanto del régimen general, como de los regímenes especiales. En ningún caso se podrán desmejorar sus salarios y prestaciones sociales;
Que el artículo 20 de la Ley $4^{\text {a }}$ de 1992 dispone que los profesores de las universidades públicas nacionales tendrán igual tratamiento salarial y prestacional, según la categoría académica exigida, dedicación y producción intelectual.

Que el artículo 77 de la Ley 30 de 1992 dispone que el régimen salarial y prestacional de los profesores de las universidades estatales u oficiales se regirá por la Ley $4^{\mathrm{a}}$ de 1992, los decretos reglamentarios y las demás normas que la adicionen y complementen.

Que el Decreto 1279 de 2002 establece el régimen salarial y prestacional de los docentes de las universidades estatales a saber: vacaciones, prima de vacaciones, bonificación por servicios prestados, prima de servicios, prima de navidad, cesantías y pensiones.

Que el Decreto 1279 de 2002 establece en su articulo 4 que los profesores de hora-cátedra de las universidades estatales $u$ oficiales distintas a la Universidad Nacional de Colombia no son empleados públicos docentes de régimen especial ni pertenecen a la carrera profesoral $y$, por consiguiente, sus condiciones salariales y prestacionales están regidas por las reglas contractuales que en cada caso se convengan, conforme a las normas internas de cada universidad, con sujeción a lo dispuesto en las disposiciones constitucionales y legales.

Que el artículo 73 de la Ley30 de 1992 disponeque los profesores de cátedra no son empleados públicos ni trabajadores oficiales.

Que la Corte Constitucional en la Sentencia C-006 de 1996 determínó que los a los profesores de cátedra se les deben reconocer y pagar todas las prestaciones sociales y factores salariales que la Ley reconoce a los profesores de carrera, en proporciónal tiempolaborado.

Que se hace necesario reglamentar el reconocimiento de las prestaciones sociales de los catedráticos de la institución. 


\section{ACUERDA:}

ARTICULO $1^{\circ}$. El valor de la hora para los docentes de cátedra de la Universidad XXXX, será determinada por el Comité de Asignación de Puntaje con base en la categoría establecida por el Comité de Selección y Evaluación Docente y el Decreto1279 de 2002 o en las normas que lo adicionen o modifiquen.

El procedimiento para determinar el valor de la hora cátedra se obtiene de multiplicar los puntos asignados, por el Comité de Asignación de Puntaje; por el valor del mismo determinado por el Gobierno Nacional y se divide por 180 .

Parágrafo: El valor del punto de que trata el presente artículo será fijado por el Gobierno Nacional, y corresponde al valor del punto aplicable a los docentes de las universidades estatales u oficiales de que trata el Decreto 1279 de 2002, o las normas que lo modifiquen o sustituyan.

ARTÍCULO 2. Reconocer a los profesores catedráticos las prestaciones sociales que se reconocieren a los demás docentes de planta de la Universidad consignadas en el Decreto 1279 de 2002 o en las normas que lo modifiquen 0 sustituyan, siempre en proporción al tiempo efectivamente laborado.

Parágrafo. El reconocimiento proporcional de las prestaciones a favor de los docentes de cátedra implicará la conversión a días del número de horas efectivamente laboradas.

ARTíCULO 3. El presente Acuerdo rige a partir de su publicación.

Dado en , a los__ días del mes de de dos mil nueve (2009).

\section{PRESIDENTE}

\section{SECRETARIA}

\section{$1.7 \quad$ Conclusiones}

El propósito de este ensayo ha sido desarrollar uno de los temas más preocupantes de los docentes catedráticos de las universidades públicas en Colombia con base en decisión de la Corte Constitucional de Colombia, corporación que mediante Sentencia C-006 de 1996, determino que a los profesores de cátedra se les deben reconocer y pagar todas las prestaciones sociales y factores salariales que la Ley reconoce a los profesores de carrera, en proporción al tiempo laborado.

Consideró la Corte Constitucional que los profesores catedráticos son servidores públicos que están vinculados a un servicio público y en consecuencia, los respectivos actos administrativos determinarán las modalidades y efectos de su relación jurídica de acuerdo con la Ley.

Los profesores de cátedra tienen también una relación laboral subordinada, por cuanto cumplen una prestación personal de servicio, igual a la que realizan los profesores de tiempo completo, de medio tiempo o los llamados ocasionales a que se refiere el artículo 74 de la Ley 30 de 1992 . Ellos devengan una remuneración por el trabajo desempeñado y están sujetos a una subordinación como se les exige a los otros docentes, como horario, reuniones, evaluaciones, etc., contemplados en los reglamentos.

Con el fin de determinar el valor de la hora cátedra dándole estricto cumplimiento a la sentencia C006/96, se debe inicialmente establecer la categoría del docente catedrático universitario y luego se establecen los puntos a que tiene derecho, de conformidad con el artículo 6 del Decreto 1279 de 2002.

Determinado el valor de la hora cátedra, la jurisdicción ha accedido a reconocer a título de INDEMNIZACIÓN ${ }^{17}$, el equivalente a las prestaciones sociales que perciben los docentes oficiales en términos proporcionales al trabajo desempeñado.

\footnotetext{
${ }^{17}$ Lo anterior con el fundamento jurídico de que los profesores catedráticos no forman parte de las plantas de personal de las universidades públicas a quien se les reconoce salarios y prestaciones sociales y quienes tienen un régimen legal previamente establecido
} 
A partir de la evolución histórica legal de la vinculación de los profesores catedráticos universitarios nos permitimos llegar a proponer un modelo de Acuerdo por el cual se aprueba el Régimen prestacional del Profesor de Cátedra de la universidades públicas en Colombia que hoy sometemos a la consideración y análisis de la comunidad académica, con la seguridad de que podamos obtener un Acto administrativo que, favoreciendo la dignidad del profesor universitario, conduzca a mejorar la calidad de la educación por ellos impartida.

\section{BIBLIOGRAFÍA}

- ACUERDO NO 031 de 1994, Universidad del Tolima

- ACUERDO N049 de 1995, Universidad del Quindío

- ACUERDO NO.046 de 2002, Universidad de Pamplona

- ACUERDO NO 059 de 2002, Universidad de laAmazonia

- ACUERDO NO. 018 de 2003, Universidad del Cauca

- ACUERDO NO 253 de 2003, Universidad de Antioquia

- ACUERDO NO. 024 de 2003, Universidad del Valle

- ACUERDO NO 007 de 2003, Universidad del Magdalena

- ACUERDONO. 29 de 2004, Universidad Tecnológica de Pereira

- ACUERDO NO 009 de 2004, Escuela Superior de Administración Pública-ESAP

- ACUERDO 002 del 2004, Universidad de los LLanos

- ACUERDO N016 de 2005, Universidad Nacional de Colombia

- ACUERDONO 201 de 2005, Universidad de Caldas

- ACUERDO NO.026 de 2005, Universidad Francisco de Paula Santander

- ACUERDO NO 08 de 2008, Universidad Militar Nueva Granada

- ACUERDONO.68 de 2008, Universidad Industrial de Santander

- ACUERDO NO.15 de 2009, Universidad Pedagógica y Tecnológica de Colombia

- ACUERDO NO. 15 de 2009, Universidad Surcolombiana

- CORTE CONSTITUCIONAL. Sentencia C- 133/93 abril 1 de 1993. Tema: Inconstitucionalidad del artículo 19 de la Ley $4^{\mathrm{a}}$ de 1992. Magistrado Ponente Dr. Vladimiro Naranjo Mesa.

- CORTE CONSTITUCIONAL. Sentencia No. C-521/95. Magistrado Ponente: Dr. Antonio Barrera Carbonell.

- CORTE CONSTITUCIONAL, Sentencia C-073/03 Magistrado Ponente: Dr. Manuel José Cepeda Espinosa, expediente D-4270, cuatro (04) de febrero de dos mil tres (2003).

- CONSEJO DE ESTADO, Sección Cuarta, Radicación 7276, sentencia de 13 de octubre de 1995. Magistrado Ponente Dr. Julio Enrique Correa Restrepo.

- CONSEJO DE ESTADO, Sección Segunda Subsección "A", Bogotá, D.C., veintiséis (26) de enero de dos mil seis (2006), Exp.: 25000232500020011068801. Magistrada Ponente: Ana Marganta Olaya Forero.

- CONSEJO DE ESTADO, Sala de lo Contencioso Administrativo, Sección Segunda-Subsección "B", Bogotá. D.C., veintiocho (28) de agosto del dos mil tres (2003), Radicación número: 73001-23-31-0001999-0454-01. Magistrado Ponente: Tarsicio Cáceres Toro.

- CONSEJODE ESTADO - Sala de Consulta y Servicio Civil Radicación 880 de 1996.

- CASTRO, Jaime. (2007). Constitución Política de Colombia, Ediciones Universidad del Rosario, Bogotá.

- ORTEGATORRES, Jorge. (1990). Código Sustantivo del Trabajo, Editorial Temis, Bogotá.

- PÉREZ PUENTE Leticia. (1958). De maestros y discípulos: México, siglos XVI-XIX, Universidad Nacional Autónoma de México. Centro de Estudios sobre la Universidad, México, pags.1-252. 
- RAMÍREZ PLAZAS, Jaime. (2009). La Determinación del Salario y EI Papel del Estado en una Economía de Mercado, RevistaAle-kuma vol 29-31.Medellin. pag, 29, 35.

\section{EnlaWEB}

- fenalprou.org.co/component/option,com_docman/.../gid,259/

- www.aspucol.org/.../ii_encuentro_profesores_temporales_plegable.pdf

- www.mineducacion.gov.col.../article-87802.html

- web.icfes.gov.co/web/index.php?option=com_docman

- www.dmsjuridica.com/JURISPRUDENCIA $. . . / 22130 \% 20 . d o c$

- www.dmsjuridica.com/JURISPRUDENCIA/SALA.../10837.doc

- www.rhela.rudecolombia.edu.co/index.php/rhela/article/view/.../26

- asLeyes.com/descargas/pdf/periodico/maestro_legal_03.pdf

- Red de Revistas Científicas de América Latina y el Caribe, España y Portugal Sistema de Información Científica Redalyc 